\title{
The Effect of Explicit English Morphology Instruction on EFL Secondary School Students' Morphological Awareness and Reading Comprehension
}

\author{
Mohamed Farrag Ahmed Badawi ${ }^{1}$ \\ ${ }^{1}$ Curriculum \& EFL Instruction, Faculty of Education, October 6 University, Egypt \\ Correspondence: Mohamed Farrag Ahmed Badawi, Curriculum \& EFL Instruction, Faculty of Education, \\ October 6 University, Egypt
}

Received: January 16, 2019

Accepted: March 19, 2019 Online Published: March 21, 2019

doi: 10.5539/elt.v12n4p166

URL: https://doi.org/10.5539/elt.v12n4p166

\begin{abstract}
The study attempted to investigate the effect of explicit morphology instruction (EMI) on developing secondary school students' EFL morphological awareness and reading comprehension. The explicit morphology instruction targeted two morphological skills namely, inflectional and derivational skills. The study used a pre-posttest experimental and control group design. The intact study participants were (98) first year secondary school students. While the first intact group $(\mathrm{n}=49)$ was functioned as an experimental group, the second intact group $(\mathrm{n}=49)$ represented the control group. To collect the data, a two-unit explicit morphology instruction program (EMIP), a morphological awareness test (MAT) and a reading comprehension test (RCT) were designed, validated and implemented. Before the intervention, the participants' morphological awareness and reading comprehension were pre-tested. During the course of intervention, while the experimental group participants were exposed to explicit morphological instruction in addition to their regular English instruction sessions, the participants of the control group only received their regular EFL instruction sessions. Results revealed that the experimental group participants' mean scores on the post morphological awareness test and reading comprehension test surpassed that of the control group. Accordingly, explicit morphological instruction was effective in developing EFL secondary school students' morphological awareness and reading comprehension. However, the effect size of explicit morphological instruction on developing EFL secondary school students' morphological awareness was higher than its effect size on developing their reading comprehension. Therefore, teaching English morphology should be an integral part of EFL secondary school curriculum.
\end{abstract}

Keywords: explicit instruction, morphological awareness, reading comprehension, EFL learners

\section{Introduction}

At present, explicit instruction of language form (Words in italic are to emphasis their idiomatic use) is no longer a common practice in many EFL classrooms. Such marginalization may be due to the claim that a large number of EFL teachers and material developers have misunderstood or misused Communicative Language Teaching (CLT). CLT approach rests on the theory that the key function of language use is communication. Simply, it focuses on fluency and meaning. Despite the fact that the CLT does not exclude the instruction of language form, many EFL teachers advocating CLT used to exclude language form instruction. Mistakenly, they have used fluency to displace accuracy and language meaning to exclude language form instruction. This is, however, a mistaken view because 'fluency' and 'accuracy' cannot be kept separate. That is to say, the purpose of communicative tasks is not just fluency development. Performing communicative tasks should contribute to linguistic development. This cannot occur automatically. It requires focus on form. As a result of such faulty practices, language form genres have been marginalized in EFL classrooms. For Ellis (2001), form-focused instruction is to induce language learners to pay attention to linguistic form. Focus on form should not be overlooked in the learning process. Therefore, balanced corrective measures are required to allow explicit instruction of language form such as grammar, vocabulary, recast error correction, phonology and morphology to come back to EFL classrooms under the regulative umbrella of the CLT.

Central to language forms that should come back to EFL classrooms is Morphology. Morphology is one of the recent linguistic genres that has positive pedagogical implications in first and foreign language instruction. 
Linguistically, morphology is concerned with the internal structure and meaning of words. Pedagogically, EFL learners who understand how English words are formed by combining prefixes, suffixes and roots are subject to acquire more English words and easily comprehend reading texts than those who do not have such morphological knowledge. Subsequently, teaching English morphological skills in EFL classrooms helps improve EFL students' English vocabulary, reading comprehension, spelling quality, and writing performance. That is to say, EFL learners who have developed morphological awareness would be able to recognize the relation among read, reread, reader, reading, reads, and pre-reading. They are related to the root read. The meaning of all these words is linked to the act of reading. Hence, empowering EFL learners with morphological awareness facilitates EFL instruction.

Recently, morphological awareness research suggests that there is a significant degree of achievement among students who are exposed to strategies for not only understanding the meanings of words but also recognizing different morphological forms of the same word in reading texts, as opposed to students who are not exposed to such strategies $(\mathrm{Oz}, 2014)$. Research on reading and morphological awareness reveals that, in many cases, learners with the ability to break words into their meaningful parts not only build up their vocabulary but also have better reading comprehension (Kieffer \& Lesaux, 2007; Karimi, 2012). Likewise, English native speakers' research has also shown that morphological awareness plays a stronger role in reading development (Deacon \& Kirby, 2004). Such encouraging evidence motivated the present study to investigate the effect of explicit morphology instruction on developing EFL Egyptian secondary school students' morphological awareness and reading comprehension.

\section{Context of the Problem}

In Egypt, like many other countries, EFL instruction is totally dominated by Communicative Language Teaching. Unfortunately, a quite large number of EFL teachers and material developers have misunderstood or misused CLT. They mistakenly believe that word form or morphological awareness can be implicitly learned or can be automatically acquired. Accordingly, the explicit instruction of word form is hardly noticed in EFL classrooms. Simply, the way the EFL textbooks are written is the way EFL teachers teach. Again, the CLT does not exclude explicit instruction of language forms especially when such forms are presented in meaningful and communicative contexts.

As a faculty member at October 6 University and a teaching practicum supervisor, the researcher visited more than (51) EFL classrooms in (17) secondary schools in $6^{\text {th }}$ October City along the first and the second semester in the academic year 2017-2018. Among the researcher's observations is that neither the objectives nor the content of the three assigned EFL secondary school textbooks are concerned with morphology instruction. Such exclusion may be due to EFL teachers' mistaken perception of CLT. Other EFL teachers do not teach morphology since it is not a part of the current EFL curriculum. In short, it could be concluded that Egyptian EFL secondary school students do not receive any regular explicit morphology instruction. Another aspect of word form instructional problem is that there is no real established methodology for teaching word form, as there is with teaching grammar for instance.

Therefore, most of, if not all, EFL students have no chance to benefit from the pedagogical advantages of morphological awareness that can facilitate EFL instruction. Furthermore, teaching word internal structure can help develop EFL students' fluency, reading, editing skills and vocabulary. As long as teaching word form is an immense issue, why then do EFL teachers spend so little time on it? Accordingly, urgent practical measures are required to make good use of morphology instruction to better teach and learn English language in EFL classrooms. In line with this interest, McLeod and Apel (2015) emphasize the need for morphological instruction in language literacy program.

\section{Statement of the Problem}

Explicit instruction of English morphology to develop EFL first year secondary school students' EFL literacy skills seems to be marginalized in the Egyptian context. Accordingly, the current study attempted to investigate the effect of explicit morphology instruction on developing EFL Egyptian secondary school students' morphological awareness and reading comprehension.

\section{Questions of the Study}

The study attempted to answer the following questions:

1) What are the features of the suggested explicit instruction morphology program?

2) What is the effect of the suggested explicit morphological instruction program on developing EFL first year secondary school students' morphological awareness? 
3) What is the effect of the suggested explicit morphological instruction program on developing EFL first year secondary school students' Reading Comprehension?

\section{Hypotheses of the Study}

The study aimed at testing the following hypotheses:

1). There is a statistically significant difference between the mean scores of the control group students and the experimental group participants on the post-RCT favoring the experimental group participants.

2). There is a statistically significant difference between the mean scores of the experimental group participants' mean scores on the pre and post RCT favoring their mean scores on the post-RCT.

3). There is a statistically significant difference between the mean scores of the control group students and the experimental group participants on the post-MAT favoring the experimental group participants.

4). There is a statistically significant difference between the mean scores of the experimental group participants' mean scores on the pre and post-MAT favoring their mean scores on the post-MAT.

\section{Aim of the Study}

The aim of the current study is to investigate the effect of explicit morphology instruction (EMI) on developing EFL first year secondary school students' morphological awareness and reading comprehension.

\section{Significance of the Study}

The present study may be one of the pioneer studies in Egypt that investigate the effect of using explicit morphology instruction for improving EFL learners' morphological awareness which in turn may improve their reading comprehension. The current study may encourage other EFL researchers to conduct more research projects to explore the effect of morphology instruction on other language skills and areas. In addition, it may draw the attention of EFL curriculum developers to recognize morphology instruction as a basic component of secondary school EFL textbooks. EFL methodologists may use various teaching morphology-based strategies to better teach vocabulary knowledge, spelling quality, reading comprehension and writing flexibility.

\section{Definitions of Terms}

\subsection{Morphology}

The current study adopted the definition that is coined by Carlisle, Goodwin and Nagy (2013) who defined morphology as the study of internal structures of words and word formation processes.

\subsection{Morphological Awareness (MA)}

Carlisle, McBride-Chang, Nagy, and Nunes, (2010, p. 466) define morphological awareness as "the ability to reflect on, analyze and manipulate the morphemic elements in words." Operationally, morphological awareness refers to Egyptian EFL first year secondary school students' ability to explain the key morphological concepts and to form or analyze English words using inflectional and derivational morphological skills.

\subsection{Reading Comprehension ( $R C$ )}

Procedurally, reading comprehension refers to EFL first year secondary school students' ability to answer a set of comprehension questions based on a reading text containing words of inflectional and derivational morphemes. Simply, comprehending the reading text requires decoding the morphological units.

\subsection{Explicit Morphology Instruction (EMI)}

Procedurally, explicit morphology instruction is a teaching strategy that allows the teacher to demonstrate inflectional and derivational morphemes as target learning items of the suggested program in a direct way. The teacher can use many resources to facilitate instruction such as YouTube Videos.

\section{Study Delimitations}

The study findings should be recognized in light of the following delimitations:

1) The operational definitions of the key terms and variables.

2) EFL Egyptian first year secondary school ( $\left(1^{\text {st }}\right.$ Semester, 2017-2018).

3) The special specifications of the suggested program.

4) The academic facilities and technical support that were available during the intervention period.

5) The size of the sample yielded to the school routines and restrictions. 


\section{Review of Literature}

The word morphology comes from Greek word morphe which means 'form' or 'shape' so that it means 'the study of form or forms' (Celik, 2007). Linguistically, morphology is frequently defined as the systematic study of the internal structure of words. Further, Carlisle, Goodwin, and Nagy (2013) define morphology as the study of internal structures of words and word formation processes. According to Carlisle (2003), words are usually made up of smaller recognizable units called morphemes. Knowing what a morpheme means helps learners to understand or infer the meaning of new words. Morphological awareness facilitates word reading and understanding since word recognition is an essential part of reading.

For Yule (2010), morphemes are the minimal units of meaning or grammatical function which are used to form new words. These units consist of morphemes. For example, the word displacement includes three morphemes. One minimal unit of meaning is \{place\} which refers to the meaning of position or location. Another minimal unit of meaning is \{dis\} that refers to apart or away. Finally, the other minimal unit is the derivational \{ment\} which converts the root into a new noun word. Idiomatically, morphemes can be free and bound. While a free morpheme can stand on its own as an independent single word such as $\{$ read $\}$, a bound morpheme cannot exist on its own and must be added to another form (Celik, 2007; Fromkin, Rodman and Hyams, 2011). That is to say, the plural morpheme $\{s\}$ can only occur when it is attached to nouns. As a general morphological rule, all English affixes are bound morphemes. Whereas prefixes are added to the beginning of another morpheme such as $\{u n\}$ in words like unable and unfair, suffixes are attached to the end of another morpheme such as $\{e r\}$ in words like reader, and writer.

Generally, bound morphemes are either derivational or inflectional. Derivational morphemes are used to create new words or "to make words of a different grammatical class from the stem" (Yule, 2010, p. 69). For example, the addition of the derivational morpheme $\{l e s s\}$ changes the word class $\{h e l p\}$ from a noun or a verb to an adjective helpless, whereas adding $\{u n\}$ to the adjective \{happy\} creates the adjective \{unhappy\} which keeps the same word class. Likewise, inflectional morphemes are used to denote some aspects of the grammatical function of a word. For example when $\{s\}$ comes as an inflectional morpheme, it changes the word from singular to plural as in $\{b o y\}$ and $\{$ boys $\}$. As seen, the two words $\{b o y\}$ to $\{$ boys $\}$ remain as noun. Meaning that inflectional morpheme does not change word category. Similarly, the words $\{$ old $\}\{$ older $\}\{$ oldest $\}$ seem different in terms of inflectional morpheme, yet they have the word category as adjectives. Shortly, as long as inflectional morphological awareness develops grammatical accuracy, derivational morphological awareness promotes students' vocabulary knowledge.

For Carlisle, (2003, p. 292), "English language is a morpho-phonemic language.” Karimi (2012, p. 452) views morphological awareness as an important component of linguistic knowledge since "morphemes have semantic, phonological and syntactic properties that clearly express the role of a particular word in its linguistic context." While Yucel Koc (2015) defines morphological awareness as the skill of utilizing morphological units correctly, Carlisle, McBride-Chang, Nagy, and Nunes (2010, p. 466) regard morphological awareness as "the ability to reflect on, analyze and manipulate the morphemic elements in words.” For Kuo and Anderson (2006), morphological awareness refers to the metalinguistic consciousness that words are constituted of individual units/morphemes which can be analyzed and manipulated in various ways.

Pedagogically, morphological instruction aims at improving morphological awareness or the awareness of morphemic structures. Kuo and Anderson, (2006) suggest that morphological awareness benefits reading comprehension, perhaps more than any other reading ability. Moreover, morphological awareness has recently been a focus in both first and foreign language literacy development (Karimi, 2012). In practice, language learners familiar with the formation of new English words through prefixes, suffixes and roots may have more words and comprehend texts better (Kieffer \& DiFelice, 2013).

For more confirmation, Brimo (2016) mentions that addressing the sub-lexical features of any given language can influence literacy skills at both lexical level such as word reading, spelling, and vocabulary and supra-lexical level such as reading comprehension and writing. In addition, it was asserted that students would easily learn English if they had solid morphological knowledge. In such doing, they would be able to break down the word to a more understandable form (Karimi, 2012). Similarly, Kieffer and Lesaux (2007) are of the opinion that students who understand how words are formed by joining suffixes, prefixes, and roots have greater breadth of vocabulary.

Likewise, Levesque, Kieffer, and Deacon (2017) and Tighe et al. (2018) state that there are direct and indirect relationships between morphological awareness and reading comprehension. According to Yucel-Koc (2015), the faster one recognizes the words, the more fluent reader he becomes. Further, some intervention studies show that 
morphological instruction can help learners build vocabulary and improve their reading skills (Goodwin \& Ahn, 2013). For Kieffer and Lesaux (2007) and Karimi (2012), in many instances, students with the ability to break words into their meaningful parts not only build up their vocabulary but also have a better comprehension of reading and therefore build up their skills in language literacy. Furthermore, morphological awareness enables students to describe complex words and infer meaning from reading comprehension texts (Ginsberg et al., 2011).

Regarding morphology instruction, researchers have emphasized the need for morphological instruction in language literacy (McLeod \& Apel, 2015; Fracasso, Bangs, \& Binder, 2016). Explicit instruction of morphology is viewed by Wilson, (2005) as an effective means to enhance applying word structure for decoding, spelling, and vocabulary study. Moreover, Carreker, (2005) mentions that students can be taught strategies to divide words according to their affixes and roots. Students may be able to identify the meaning of unfamiliar words simply by identifying the affixes and the remaining base or root of these words. In this respect, McLeod and Apel (2015) emphasize the need for morphological instruction in language literacy program. Morphological instruction can be an essential area of vocabulary instruction, vocabulary learning, and reading comprehension (Lo, Anderson, \& Bunch-Crump, 2017).

Procedurally, Prince (2009) suggests four instructional strategies for teaching morphology. Firstly, morphology should be taught as a distinct component of a vocabulary improvement program throughout the upper elementary years. Secondly, morphology should be taught as a cognitive strategy to be learned. In order to break a word down into morphemes, students must recognize that they do not know the word. Analyze the word for recognizable morphemes, both in the roots and suffixes. Think of a possible meaning based upon the parts of the word. Check the meaning of the word against the context of the reading. Thirdly, students also need to understand the use of prefixes, suffixes, and roots, and how words get transformed.

With respect to previous research, most of the morphological awareness and reading studies are relational or correlational studies. In L1 context, Levesque et al. (2017) studied English-speaking learners' ability to read and analyze the meaning of morphologically complex words including morphological decoding and analysis in relation to reading comprehension. The results demonstrated that morphological awareness contributed to reading comprehension. Levesque, Kieffer, and Deacon (2018) investigated how core skills surrounding morphemes support the development of reading comprehension among English speaking students. The findings demonstrated that students' use of morphemes to infer the meanings of unfamiliar complex words supported the development of reading comprehension. Baumann et al. (2002) investigated the effects of morphological instruction on vocabulary learning among native L1 learners. The study targeted relational aspect of derivational morphology by asking students to provide definitions of morphologically complex words that were scored based on students' recognition of the meanings of taught word parts. The results showed that students who received instruction in specific prefixes and suffixes were more successful in inferring the meaning of morphologically complex words compared to students who received direct instruction in textbook vocabulary.

With respect to morphological awareness and reading studies in EFL context, Zhang and Koda (2012) tested the direct and indirect effects of morphological awareness on English vocabulary knowledge and reading comprehension among advanced Chinese EFL readers. They found positive effects of morphological awareness on reading comprehension. In addition, Shoeib (2017) investigated levels of morphological awareness of EFL Saudi university students and tried to identify any potential relationship between their morphological awareness and successful reading comprehension. The total scores of students on morphological tests positively correlated with their total scores on reading comprehension test. Jiang et al. (2015) examined the relationship between morphological awareness and reading comprehension among adult EFL learners. Findings showed significant differences between successful and less successful adult EFL readers concerning morphological knowledge. While successful readers valued derivational morphological rules, less successful readers underestimated the importance of morphological knowledge.

Zhang (2016) studied the contribution of morphological awareness to ESL reading comprehension with young Chinese-speaking ESL learners. The results demonstrated that morphological awareness had a significant direct effect on reading comprehension over and above vocabulary knowledge and such effect became stronger over time. The study indicated an increasingly important role for morphology in ESL reading comprehension and highlighted the need for explicit teaching of morphology to facilitate ESL learners' reading development. Diaz (2010) investigated if morphological instruction was effective in accelerating the acquisition of spelling, vocabulary, and reading comprehension by English language learners and their English dominant peers. The results showed that English language learners could make significant progress in reading, vocabulary, and spelling when morphological instruction was a major part of the curriculum. Crosson et al. (2018) investigated whether morphological awareness instruction would enhance word learning outcomes of English language 
learners. The results showed that morphological problem solving of unfamiliar words had significant effects on word learning outcomes.

Generally, the above studies show the positive effects of morphological awareness on literacy, especially reading comprehension. As seen, there is a scarcity of instructional research in EFL context. Findings with L1 learners can hardly be generalized to EFL learners. Research on morphological awareness as a central focus in EFL context is rare (Hamavandi, Rezai, \& Mazdayasna, 2017).

\section{Method}

\subsection{Participants}

The study participants were (98) EFL first year secondary school students from El-Radwah Secondary School in $6^{\text {th }}$ October city, Giza, Egypt. The study participants were two intact classes. While the first intact group/class $(n=49)$ was randomly selected as the experimental group, the second intact group/class $(n=49)$ represented the control group. Pretesting revealed that the two groups were equal in terms of their reading comprehension performance and morphological awareness and where the differences between the mean scores of the two groups were insignificant.

Statistically, the mean scores of the experimental group $(\mathrm{m}=7.63)$ seems similar to that of the control group $(\mathrm{m}=8.06)$ on the pre RCT. According to the t-test results, the difference between the two mean scores is statistically insignificant where the calculated $t$ is (-1.029) and the $p$ value is $(0.3062)$. By conventional criteria, this difference $(\mathrm{P}=0.3062)$ is considered to be statistically insignificant at $95 \%$ confidence interval. This result reveals that the two groups are equal in terms of their reading comprehension level and in turn it assures the homogeneity of the study participants. Neither the mean scores of the experimental group $(\mathrm{m}=7.63)$ nor that of the control group $(\mathrm{m}=8.06)$ passed the cut-off level of success ( 10 points $=50 \%)$ on the pre-RCT. Finally, this result seems reasonable since the two groups did not receive any previous explicit instruction pertinent to utilizing morphological awareness in reading comprehension instruction.

With respect to the participants' morphological awareness, the mean scores of the experimental group (14.55) seems similar to the mean scores of the control group (15.08) on the pre-Morphological Awareness Test MAT. According to the t-test results, the difference between the two mean scores is statistically insignificant where the $t$ value is $(-0.35)$ and the $p$ value is $(0.724)$. This difference $(\mathrm{P}=0.724)$ is considered to be not statistically significant at $95 \%$ confidence interval. This result reveals that the two groups are equal in terms of their morphological awareness and this assures the homogeneity of the selected sample.

\subsection{Experimental Design}

The study used a quasi-experimental control group design, where the experimental group participants were exposed to morphology explicit instruction, the control group students just received their regular English instruction. After the intervention, the two groups were post-tested.

\subsection{Research Instruments}

\subsubsection{Morphological Awareness Test (MAT)}

\subsubsection{Aim of the MAT}

The Morphological Awareness Test (MAT) was developed to measure EFL first year secondary school students' morphological awareness. The test was designed to achieve two objectives. Firstly, the test was used to pretest the participants' morphological awareness to determine the equality and homogeneity of the two groups before the intervention. Secondly, the same test was used as a posttest to determine the participants' morphological awareness after the intervention i.e., to show the extent the proposed program was effective in developing the participants' morphological awareness.

\subsubsection{Content of the MAT}

The content of the test was prepared in light of the objectives and learning outcomes of the suggested program and the main principles of morphological awareness gained from the review of the relevant literature and related studies. The test contained two parts. Part one was devoted to testing participants' morphological knowledge. This part contained thirty True/False questions covering the key concepts of morphology. The second part was prepared to test participants' morphological practical morphological abilities via two main questions. The first question required the test takers to form new words from given roots. The second question intended to test students' abilities of word analysis using morphological rules (Appendix 2). 


\subsubsection{Validity of the MAT}

The face validity of the MAT was determined by a panel of TEFL experts who evaluated the test in light of its aim, content and layout. Having the test modified in light of the experts' remarks, the final version of the test proved valid in terms of its aim, content and layout.

\subsubsection{Reliability of the MAT}

As for the reliability of the MAT, the test re-test method was used. The MAT was administered to 48 EFL first year secondary school students from other classes that were not participating in the main study experiment. After one week, the same test was re-administered to the same students. Then, students' scores on the first administration of the test were compared to their scores on the second administration of the same test. The reliability coefficient for the test was $(\mathrm{r}=84)$. This value displayed that the test is reliable.

\subsubsection{Administration of the MAT}

A day before beginning the intervention, the MAT pre-test was administered to the participants. After the intervention that lasted for 21 days, the MAT was administered to the participants as a post-test.

\subsubsection{Scoring the MAT}

The participants' performance was scored according to two different scoring schemes. The first part of the test which contained thirty True/False questions was scored by a simple scoring scheme that is one point for correct answer and zero for incorrect one. Thus, the maximum score of the first part was 30 points. As for the first question of the second part of the test, it involved ten sub-questions where each sub-question presented a root and the test-takers must write/form at least three new words related to the same root using proper morphemes. One point was given to each correct new word. Thus, the total score of this question was 30 points. The second question contained 10 morphemic words and the test-takers should analyze them against their correct morphemes. Three points were appointed to each word correctly analyzed. Two points were given to each incomplete word analysis. While one point was given to each correct attempt, zero was appointed to each wrong attempt. Therefore, the total score of the second question was 30 points. Based on such calculations, the maximum test score was 90 points.

\subsubsection{The Reading Comprehension Test (RCT)}

\subsubsection{Aim of the RCT}

The Reading Comprehension Test (RCT) was developed to test EFL first year secondary school students' reading comprehension. The test was designed to achieve two objectives. Firstly, the test was used to pretest the participants' reading comprehension to determine the equality and homogeneity of the two groups before the intervention. Secondly, the same test was used to posttest the participants' reading comprehension after the intervention to decide the effectiveness of the proposed program in developing the participants' reading comprehension.

\subsubsection{Content of the RCT}

The content of the RCT was prepared in light of the objectives and learning outcomes of the suggested program and the main principles of reading comprehension obtained from the review of the relevant literature. The reading comprehension test included two short (about 200 words) expository texts. Each reading text contained 20 morphologically complex words $(10 \%)$. Many of these morphologically-complex words were critical in understanding the key information or the supporting details mentioned in the two reading texts. Each reading text followed by 10 multiple choice questions (MCQs) to test the participants' ability to infer the main ideas and supporting details. The total test questions were 20 pints. One point was given to each correct answer/choice (Appendix 3).

\subsubsection{Validity of the RCT}

The validity of the RCT was determined by the same panel of TEFL experts who revised the test in terms of its aim, content and layout. Having the test amended in light of the experts' remarks, the final version of the test proved valid in terms of its aim, content and layout.

\subsubsection{Reliability of the RCT}

The RCT was administered to 48 EFL first year secondary school students from the other classes that were excluded from participating in the main study experiment. After one week, the same test was re-administered to the same students. Then, students' scores on the first administration of the test were compared to their scores on the second administration of the same test. The reliability coefficient for the test was $(r=76)$. This value 
displayed that the test is reliable.

\subsubsection{Implementation of the RCT}

Two days before beginning the intervention, the RCT pre-test was administered to the participants. After the intervention, RCT was re-administered to the same participants as a post-test. Students' mean scores were calculated and compared using t-test.

\subsubsection{Scoring the RCT}

The test involved two reading texts each text followed by 10 multiple choice questions MCQs. The total RCT score was 20 points where each correct answer/choice was given one point (Appendix 3).

\subsection{The Suggested Program}

\subsubsection{Program Rationale}

The rationale behind designing a two-unit-morphology program was that morphology was not included in the assigned secondary school EFL textbooks so that it was a must to design a suggested enrichment program. It was a short program because of two reasons. First, its content was intended to cover only two morphological skills namely, inflectional and derivational skills. Second, it was taught as an extra load since it was delivered within students' daily formal school schedule. If it was a long or an extended program, most of the students would not participate in the experiment.

\subsubsection{Program Aim}

The main aim of the suggested program was to develop EFL first year secondary school students' morphological awareness and reading comprehension using explicit morphology instruction.

\subsubsection{Program Objectives}

By the end of the suggested program, EFL first year secondary school students who successfully completed the program will be able to:

1) Define the key morphological concepts.

2) Form new words using proper inflectional morphemes.

3) Form new words using proper derivational morphemes.

4) Analyze words according to morphological rules.

\subsubsection{Program Content}

In light of the objectives of the suggested program, its content was designed and organized thematically along two units (Student's Guide, Appendix: 1). While unit one was devoted to the basic morphological knowledge, unit two was intended to highlight the intended two morphological skills. The program content was supported by some YouTube Videos. Students' participation was an integral part of the program.

\subsubsection{Program Teaching Approach}

In addition to using the explicit instruction strategy to perform program teaching, the outcome-based teaching approach was applied. The outcome-based teaching approach is a pedagogical process which focuses on the achievement of certain specified results. Pang (2009, p. 122) mentions that "outcome-based [approach] therefore, is concerned with curriculum design and ensuring that the contents, delivery, activities, and assessments are all aligned to help facilitate students to attain specific intended learning outcomes." (Teacher's Guide, Appendix: 2).

Firstly, the teacher/researcher explained the objectives of the session to the students and directed their attention to the targeted learning outcomes. Then, the teacher/researcher presented the content materials using proper learning aids and activities. Secondly, the teacher/researcher re-explained the content materials allowing the students a chance to practice the focal points individually and in groups. Providing students with performance model was a must. Finally, the teacher/researcher left the floor to the students to reproduce the intended learning outcomes. In this phase, students' performance was subject to be monitored, guided and evaluated by the teacher/researcher. Finally, the teacher/researcher wrapped up and resolved students' problematic points during the session.

\subsubsection{Evaluation of Program ILOs}

The program learning outcomes were subject to formative and summative evaluation procedures. 


\subsubsection{Program Feasibility}

Having the draft version of the program prepared, a panel of three EFL professors, five EFL supervisors and fifteen EFL teachers were invited to a semi-structured focus group discussion. According to experts' remarks and comments, the program was refined and proved feasible.

\section{Results}

\subsection{Results of the Reading Comprehension Test (RCT)}

12.1.1 Verifying the First Hypothesis

Table 1. Differences between the mean scores of the experimental and the control groups on the Post-RCT

\begin{tabular}{lllllll}
\hline Group & N & Mean & SD & $t$ & $p$ & Sig. \\
\hline Post- Experimental & 49 & 15.73 & 2.79 & & & \\
Post-Control & 49 & 8.22 & 2.40 & & & Significant \\
\hline
\end{tabular}

Table 1 displays that the mean scores of the experimental group on the Post-RCT (15.73) is higher than the mean scores of the control group (8.22) on the same test. The $t$ value was 14.29 and the P value was less than 0.0001 , this difference is statistically significant. The difference between the two mean scores is considered to be statistically significant at $95 \%$ confidence interval. Statistically, the first hypothesis was accepted as it was stated: "There is a statistically significant difference between the mean scores of the control group students and the experimental group participants on the RCT post-testing favoring the experimental group participants". The detected increase in the mean scores of the experimental group on the post-RCT (15.73) could be attributed to the effectiveness of the intervention program. That is to say, the proposed program was more effective than regular English classes in developing EFL students' reading comprehension. Wisely, such result seems logical since the two groups received two different types of inputs.

12.1.2 Verifying the First Hypothesis

Table 2. Differences between the mean scores of the experimental group on the Pre and Post RCT

\begin{tabular}{lllllll}
\hline Group & $\mathrm{N}$ & Mean & SD & $t$ & $p$ & Sig. \\
\hline Pre- Experimental & 49 & 7.63 & 2.25 & & & \\
& & & & 15.82 & $<0.0001$ & Significant \\
Post-Experimental & 49 & 15.73 & 2.79 & & & \\
\hline
\end{tabular}

Table 2 displays that the mean scores of the participants of the experimental group on the Post-RCT (15.73) was higher than their mean scores of the Pre-RCT (7.63). When the $t$ value is (15.82) and the P value is less than 0.0001, the difference is statistically significant. The difference between the two mean scores is considered to be statistically significant at $95 \%$ confidence interval. Statistically, the second hypothesis was accepted as it stated: "There is a statistically significant difference between the mean scores of the experimental group participants" mean scores on the pre and post-RCT favoring their mean scores on the post RCT" The increase of the mean scores of the experimental group on the Post-RCT could be attributed to the effectiveness of the intervention program in developing EFL students' reading comprehension. It could be concluded that the proposed program was more effective than regular English classes in developing EFL students' reading comprehension.

\section{The Effect Size of Explicit Morphology Instruction on Reading Comprehension}

To estimate the effect size of explicit morphology instruction on developing EFL English majors' reading comprehension, Blake's modified gain ratio was used.

$$
\text { Blake's MGR }=\frac{15.73-7.63}{20-7.63}+\frac{15.73-7.63}{20}=1.28
$$


Table 3. The effect size of explicit morphology instruction on reading comprehension (Blake's MGR)

\begin{tabular}{lllll}
\hline $\boldsymbol{\Sigma}$ Test Score & Pre-test Mean & Post-test Mean & M. Gain Ratio & Sig. \\
\hline 20 & 7.63 & 15.73 & 1.06 & Mine Accepted Value $=1.2$ \\
\hline
\end{tabular}

As seen, Table 3 shows that the effect size of explicit morphology instruction on developing EFL English majors' reading comprehension is (1.06) which is slightly below Blake's minimum accepted value is (1.2). That is to say, explicit morphology instruction has little effect size of on developing EFL English majors' reading comprehension.

\subsection{Results of the Morphological Awareness Test MAT}

12.2.1 Verifying the Third Hypothesis

Table 4. Differences between the mean scores of the experimental and the control groups on the Post-MAT

\begin{tabular}{lllllll}
\hline Post/Group & $\mathrm{N}$ & Mean & SD & $t$ & $p$ & Sig. \\
\hline Post-Experimental & 49 & 67.6 & 12.85 & & & \\
Post-Control & 49 & 17.96 & 7.76 & & & \\
\hline
\end{tabular}

Table 4 shows that the mean scores of the experimental group (67.6) surpassed the mean scores of the control group (17.96) on the post-Morphological Awareness Test MAT. According to the t-test results, the difference between the two mean scores is statistically significant where the $t$ value is $(23.03)$ and the $p$ value is $(<0.0001)$. This difference $(\mathrm{P}<0.0001)$ is considered statistically significant at $95 \%$ confidence interval. In light of this result, the study third hypothesis was accepted as it was stated: "There is a statistically significant difference between the mean scores of the control group participants and the experimental group participants on the post-MAT favoring the experimental group participants". That is to say, explicit morphology instruction was effective in developing EFL students' morphological awareness.

\subsubsection{Verifying the Fourth Hypothesis}

Table 5. Differences between the mean scores of the experimental group on the Pre and Post MAT

\begin{tabular}{lllllll}
\hline Group & $\mathrm{N}$ & Mean & SD & $t$ & $p$ & Sig. \\
\hline Pre- Experimental & 49 & 14.55 & 7.65 & & & \\
& & & & 24.63 & $<0.0001$ & Significant \\
Post-Experimental & 49 & 67.2 & 12.85 & & & \\
\hline
\end{tabular}

Table 5 displays that the mean scores of the participants of the experimental group on the Post-MAT (67.2) is higher than their mean scores of the Pre-RCT (7.65). By conventional criteria, when the $t$ value is (24.63) and the $P$ value is less than 0.0001 , the difference is statistically significant. Conventionally, the difference between the two mean scores is considered to be statistically significant at $95 \%$ confidence interval. Statistically, the fourth hypothesis was accepted as it was stated: "There is a statistically significant difference between the mean scores of the experimental group participants' mean scores on the pre and post-MAT favoring their mean scores on the post-MAT". The increase of the mean scores of the experimental group on the Post-MAT could be attributed to the claim that explicit morphology instruction was effective in developing EFL students' morphological awareness.

\section{The Effect Size of Explicit Morphology Instruction on Morphological Awareness}

To estimate the effect size of explicit morphology instruction on developing EFL English majors' morphological awareness, Black's modified gain ratio was used. 


$$
\text { Blake's MGR }=\frac{67.2-14.55}{90-14.55}+\frac{67.2-14.55}{90}=1.28
$$

Table 6. The Effect Size of Explicit Morphology Instruction on Morphological Awareness (Blake's MGR)

\begin{tabular}{lllll}
\hline $\boldsymbol{\Sigma}$ Test Score & Pre-test Mean & Post-test Mean & M. Gain Ratio & Sig. \\
\hline 90 & 17.97 & 67.2 & 1.28 & Min. Accepted Value $=1.2$
\end{tabular}

Table 6 shows that the effect size of explicit morphology instruction on developing EFL English majors' morphological awareness is (1.28) which is above Black's minimum accepted value (min. $=1.2$ and max. $=2$ ). That is to say, explicit morphology instruction was effective in developing EFL English majors' morphological awareness.

\subsection{Discussion of Results}

According to the $t$ values of the pre-intervention tests and post-intervention tests, explicit morphological instruction was effective in developing EFL secondary school students' morphological awareness and reading comprehension. Such result is in line with the findings of some previous research that has confirmed positive relational link between morphological awareness and reading comprehension in ESL and EFL contexts respectively (e.g. Zhang \& Koda, 2012; Shoeib, 2017).

However, such evidence could be misleading for two reasons. First, most of morphological awareness studies in EFL contents were relational not instructional/interventional. Second, even though there were few previous studies that investigated the effect of explicit morphology instruction, most of those studies failed to report the effect size. Thus, it is impossible for readers/researchers to estimate how practically significant the findings were. Statistically, while a $P$ value can inform the reader whether an effect exists, the $P$ value will not reveal the size of the effect. In reporting the findings of studies, both the substantive significance (effect size) and statistical significance ( $P$ value) are essential to be reported. Huck (2004) cautions that "a result that is deemed to be statistically significant can be, at the same time, completely devoid of any practical significance whatsoever" (p. 180). That is why the findings of the present study were supported with both the statistical significant ( $P$ and $t$ values) and Blake's effect size modified gain ratio. Empirically, the explicit morphological instruction was effective in developing EFL secondary school students' morphological awareness and reading comprehension in light of $p$ and $t$ values. However, the effect size of explicit morphological instruction on developing EFL secondary school students' morphological awareness was higher than its effect size on developing their reading comprehension.

\section{Conclusion}

The present study investigated the effect of explicit morphology instruction (EMI) on developing secondary school students' EFL morphological awareness and reading comprehension. Results revealed that the explicit morphological instruction was effective in developing EFL secondary school students' morphological awareness and reading comprehension. However, the effect size of explicit morphological instruction on developing EFL secondary school students' morphological awareness was higher than its effect size on developing their reading comprehension. The participants of the experimental group who received morphological instruction were better in analyzing derived and inflected words than that of the control group. Accordingly, it could be concluded that explicit morphological instruction contributes to EFL language learning.

Generally, the findings of the present study should not be generalized because of some limitations and restrictions. Firstly, the size of study sample was relatively small and that limited the generalization of the study findings. Second, the school in which the experiment was strict concerning the intervention duration. Thirdly, no attempt was made to control the participants' proficiency of EFL. Despite of these limitations, the findings of the present study may build a solid foundation for more profound and refined future research.

Accordingly, more research should be carried out to investigate the effect of morephonological awareness on other EFL skills in all different schooling stages. In other words, as long as this study was conducted with secondary school EFL students, it would be interesting to see how it would be effective with EFL learners in other levels of proficiency. In addition, the findings of the present study have implications for EFL teachers and textbook writers. For EFL secondary school teachers, it is advisable that they should provide explicit morphological instruction. For textbook designers, it is recommended that they incorporate a section in secondary school textbooks that can promote morphological awareness. That is to say, teaching English morphology should be an integral part of EFL secondary school curriculum. More training sessions are required to train EFL teachers to better teach morphology in secondary schools. To sum up, providing EFL learners with comprehensive explicit 
morphological training might be one of the most important educational implications of the present study.

\section{References}

Baumann, J. F., Edwards, E. C., Font, G., Tereshinski, C. A., Kame'enui, E. J., \& Olejnik, S. (2002). Teaching morphemic and contextual analysis to fifth-grade students. Reading Research Quarterly, 37, 150-176. https://doi.org/ 10.1598/RRQ.37.23

Carlisle, J. F. (2003). Morphology matters in learning to read: A commentary. Reading Psychology, 24, 291-332. https://doi.org/10.1080/02702710390227369

Carlisle, J. F., Goodwin, A. P., \& Nagy, W. (2013). Morphological knowledge and literacy acquisition. Journal of Learning Disabilities, 47(1), 3-12. https://doi.org/ 10.1177/0022219413509967

Carlisle, J. F., Goodwin, A. P., \& Nagy, W. (2013). Morphological knowledge and literacy acquisition. Journal of Learning Disabilities, 47(1), 3-12. https://doi.org/10.5539/elt.v12n2p17

Carlisle, J. F., McBride-Chang, C., Nagy, W., \& Nunes, T. (2010). Effects of instruction in morphological awareness on literacy achievement: An integrative review. Reading Research Quarterly, 45, 464-487. https://doi.org/10.1598/RRQ.45.4.5

Carreker, S. (2005). Teaching reading: Accurate decoding and fluency. In J. R. Birsh (Ed.), Multisensory teaching of basic language skills (2nd ed., pp. 43-81). Baltimore, MD: Paul H. Brookes.

Celik, M. (2007). Linguistics for students of English: Book I. Ankara: EDM.

Crosson, A. C., McKeown, M. G., Moore, D. W., \& Ye, F. (2018). Extending the bounds of morphology instruction: Teaching Latin roots facilitates academic word learning for English learner adolescents. Reading and Writing, 1-39. https://doi.org/10.1007/s11145-018-9885-y

Deacon, S. H., \& Kirby, J. R. (2004). Morphological awareness: Just "morephonological"? The roles of morphological and phonological awareness in reading development. Applied Psycholinguistics, 25, 223-238. https://doi.org/10.1017/S0142716404001110

Diaz, I. (2010). The effect of morphological instruction in improving the spelling, vocabulary, and reading comprehension of high school English Language Learners (ELLs). (Doctoral Dissertation). Available from ProQuest Dissertations and Thesis. (UMI No.3405091).

Ellis, R. (2001). Introduction: Investigating form-focused instruction. Language Learning, 57(1), 1-46. https://doi.org/10.1111/j.1467-1770.2001.tb00013.x

Fracasso, L. E., Bangs, K., \& Binder, K. S. (2016). The contributions of phonological and morphological awareness to literacy skills in the adult basic education population. Journal of Learning Disabilities, 49(2), 140-151. https://doi.org/10.1177/0022219414538513

Ginsberg, D., Honda, M., \& O’Neil, W. (2011). Looking beyond English: Linguistic inquiry for English language learners. Language and Linguistics Compass, 5(5), 249-264. https://doi.org/10.1111/j.1749-818X.2011. 00271.x

Goodwin, A. P., \& Ahn, S. (2013). A meta-analysis of morphological interventions in English: Effects on literacy outcomes for school-age children. Scientific Studies of Reading, 77(4), 257-285. https://doi.org/10.1080/ 10888438.2012.689791

Hamavandi, M., Rezai, M. J., \& Mazdayasna, G. (2017). Dynamic assessment of morphological awareness in the EFL context. Cogent Education, 4(1), 1324254. https://doi.org/10.1080/2331186X.2017.1324254

Huck, S. (2004). Reading Statistics and Research (4th ed.). New York, NY: Pearson Education Inc.

Jiang, Y., Kuo, L., \& Sonnenburg-Winkler, S. L. (2015). Morphological awareness and reading comprehension: A qualitative study with adult EFL learners. International Journal of Language and Linguistics, 2(5), 18-26.

Karimi, M. N. (2012). Enhancing L2 students' listening transcription ability through a focus on morphological awareness. Journal of Psycholinguistic Research, 42(5), 451-459. https://doi.org/10.1007/s10936-0129227-1

Kieffer, M. J., \& DiFelice Box, C. (2013). Derivational morphological awareness, academic vocabulary, and reading comprehension in linguistically diverse sixth graders. Learning and Individual Differences, 24, 168-175. https://doi.org/10.1016/j.lindif.2012.12.017

Kieffer, M. J., \& Lesaux, N. K. (2007). Breaking down words to build meaning: Morphology, vocabulary, and 
reading comprehension in the urban classroom. The Reading Teacher, 61(2), 134-144. https://doi.org/10. 1598/RT.61.2.3

Kuo, L., \& Anderson, R. C. (2006). Morphological awareness and learning to read: A cross-language perspective. Educational Psychologist, 41, 161-180. https://doi.org/10.1207/s15326985ep4103_3

Levesque, K. C., Kieffer, M. J., \& Deacon, S. H. (2017). Morphological awareness and reading comprehension: Examining mediating factors. Journal of experimental child psychology, 160, 1-20. https://doi.org/10.1016/j. jecp.2017.02.015

Levesque, K. C., Kieffer, M. J., \& Deacon, S. H. (2018). Inferring meaning from meaningful parts: The contributions of morphological skills to the development of children's reading comprehension. Reading Research Quarterly. https://doi.org/10.1002/rrq.219

Lo, Y., Anderson, A. L., \& Bunch-Crump, K. (2017). Building vocabulary of English learners with reading disabilities through computer-assisted morphology instruction. Intervention in School and Clinic, 52(3), 133-140. https://doi.org/10.1177/1053451216644829

McBride-Chang, C. (2004). Children's literacy development. London, England: Edward Arnold/Oxford Press.

McLeod, A. N., \& Apel, K. (2015). Morphological awareness intervention study of a child with history of speech and language disorders. Communication Disorders Quarterly, 36(4), 208-218. https://oi.org/10.1177/ 1525740114560371

Nagy, W. E., Beminger, V., Abbott, R., \& Vaughan, K. (2003). Relationship of morphology and other language skills to literacy skills in at-risk second-grade readers and at-risk fourth-grade writers. Journal of Educational Psychology, 95(4), 730-742. http://dx.doi.org/10.1037/0022-0663.95.4.730

Oz, Huseyin (2014): Morphological Awareness and Some Implications for English Language Teaching. Procedia - Social and Behavioral Sciences, 136, 98-103. https://doi.org/10.1016/j.sbspro.2014.05.296

Pang, M. (2009). Learning approaches and outcome-based teaching and learning: A case study in Hong Kong, China. Journal of Teaching in International Business, 20(2), 106-122. https://doi.org/10.1080/0897593090 2827825

Prince, R. E. C. (2009). Usable knowledge from Harvard Graduate School of Education - Morphological analysis: New light on a vital reading skill, HGSE Nonie Lesaux. Retrieved from http://www.uknow.gse. harvard.edu/teaching/TC102-407.html

Shoeib, A. (2017). Morphological awareness and its association with reading comprehension of EFL Saudi university students. European Journal of English Language Teaching, 3(2), 52-77.

Wilson, B. A. (2005). Instruction for older students struggling with reading. In J. R. Birsh (Ed.), Multisensory teaching of basic language skills (2nd ed., pp. 319-344). Baltimore, MD: Paul H. Brookes.

Yucel-Koc, M. (2015). The role of morphological awareness in academic vocabulary and reading comprehension skills of adult ESL learners. (Doctoral Dissertation). Available from ProQuest Dissertation and Theses database. (UMI No.3664492).

Yule, G. (2010). The study of language (4th ed.). Cambridge, England: Cambridge University Press. https://doi.org/10.1017/CBO9780511757754

Zhang, D. (2016). Derivational morphology in reading comprehension of Chinese-speaking learners of English: A longitudinal structural equation modeling study. Applied Linguistics, 38(6), 871-895. https://doi.org/10.1093/applin/amv072

Zhang, D., \& Koda, K. (2012). Contribution of morphological awareness and lexical inferencing ability to L2 vocabulary knowledge and reading comprehension among advanced EFL learners: Testing direct and indirect effects. Reading and Writing, 25(5), 1195-1216. https://doi.org/10.1007/s11145-011-9313-z

\section{Copyrights}

Copyright for this article is retained by the author(s), with first publication rights granted to the journal.

This is an open-access article distributed under the terms and conditions of the Creative Commons Attribution license (http://creativecommons.org/licenses/by/4.0/). 